Article

\title{
Is Neuropathic Pain a Good Marker of Peripheral Neuropathy in Hospice Patients with Advanced Cancer? The Single Center Pilot Study
}

\author{
Joanna Drat-Gzubicka ${ }^{1, *}$, Anna Pyszora ${ }^{2}$, Jacek Budzyński ${ }^{3}$, , David Currow ${ }^{4}$ and Małgorzata Krajnik ${ }^{2}$ \\ 1 Neurology Department, Specialist Hospital, ul. Leśna 10, 89-606 Chojnice, Poland \\ 2 Department of Palliative Care, Collegium Medicum in Bydgoszcz, Nicolaus Copernicus University in Torun, \\ ul. Skłodowskiej-Curie 9, 85-094 Bydgoszcz, Poland; anna.pyszora@cm.umk.pl (A.P.); \\ malgorzata.krajnik@cm.umk.pl (M.K.) \\ 3 Department of Vascular and Internal Diseases, Collegium Medicum in Bydgoszcz, Jan Biziel University \\ Hospital No 2, Nicolaus Copernicus University in Toruń, ul. Ujejskiego 75, 85-168 Bydgoszcz, Poland; \\ jb112233@cm.umk.pl \\ 4 IMPACCT, Faculty of Health, University of Technology Sydney, 2007 Ultimo, Australia; \\ David.Currow@uts.edu.au \\ * Correspondence: asiadrat72@gmail.com
}

Citation: Drat-Gzubicka, J.; Pyszora, A.; Budzyński, J.; Currow, D.; Krajnik, M. Is Neuropathic Pain a Good Marker of Peripheral Neuropathy in Hospice Patients with Advanced Cancer? The Single Center Pilot Study. Diagnostics 2021, 11, 1377. https:// doi.org/10.3390/diagnostics11081377

Academic Editor: Daniele Coraci

Received: 24 June 2021

Accepted: 28 July 2021

Published: 30 July 2021

Publisher's Note: MDPI stays neutral with regard to jurisdictional claims in published maps and institutional affiliations.

Copyright: (C) 2021 by the authors. Licensee MDPI, Basel, Switzerland. This article is an open access article distributed under the terms and conditions of the Creative Commons Attribution (CC BY) license (https:// creativecommons.org/licenses/by/ $4.0 /)$.

\begin{abstract}
Neuropathic pain (NP) affects approximately $30 \%$ of patients with advanced cancer. The prevalence of neuropathic pain related to peripheral neuropathy (NP-RPN) in these patients is not known. The aim of the study was to evaluate NP-RPN prevalence in hospice patients and to find out whether the absence of this pain is sufficient to rule out peripheral neuropathy. The study included a total of 76 patients with advanced cancer who were cared for at inpatient hospices. All patients were asked about shooting or burning pain (of the feet and hands), were examined systematically for sensory deficits and had a nerve conduction study performed. NP-RPN was found in $29 \%$ of the patients. Electrophysiologically-diagnosed peripheral neuropathy was found in $79 \%$ of patients, and the diagnostic electrophysiological criteria for neuropathy were met by one half of the patients without NP-RPN. The severity of NP-RPN was correlated with the clinically assessed severity of sensory neuropathy and the Karnofsky score, but was not correlated with the intensity of the clinical signs of motor neuropathy. The presence of NP-RPN did not reflect greater prevalence of motor and sensory abnormalities in neurological and electrophysiological examinations. The absence of NP-RPN did not rule out polyneuropathy in hospice patients.
\end{abstract}

Keywords: neuropathic pain; peripheral neuropathy; electrophysiology; advanced cancer; palliative care

\section{Introduction}

Neuropathic pain (NP) is defined as pain arising as a direct consequence of a lesion or disease affecting the somatosensory system [1]. Up to $10 \%$ of the general population experience NP [2,3]. The diagnosis is primarily based on clinical findings [4]. A careful, focused history and an examination of the signs characteristic of NP are therefore crucial. Imaging techniques and electrophysiological examinations can support the clinical diagnosis.

The access to these examinations is limited in people admitted to hospices. This is one reason that NP prevalence data concerning patients with end-stage cancer are lacking. In one systematic review, the prevalence of neuropathic pain as the predominant type of pain in patients with cancer-related pain ranged from 19\% (if pure) to $39 \%$ (if mixed) [5]. The prevalence of cancer NP among hospice patients with cancer pain was $>30 \%$. In another study, the prevalence of NP in patients with advanced cancer admitted to palliative care units in Japan was 18.6\% [6-8]. 
$\mathrm{NP}$ in cancer patients is a relatively broad term. It involves both central and peripheral causes of pain. Neuropathic pain related to peripheral neuropathy (NP-RPN) is just one type of peripheral neuropathic pain. Other types include: trigeminal or postherpetic neuralgia, peripheral nerve injury or radiculopathies [2]. The mechanism by which cancer might contribute to distal (not only painful) neuropathy is intriguing. Subclinical paraneoplastic syndrome, tumor-derived factors or inflammatory response to the disease may all play a role [9]. In $64 \%$ of cases, neuropathic cancer pain was caused by cancer per se, and in $20 \%$ of cases by treatment, such as chemotherapy, radiotherapy and oncological surgery $[5,10]$. In bortezomib-treated patients, NP-RPN occurs in up to $47 \%$ of patients. The respective values for platinum derivatives, taxanes and vinca alkaloids are $5-50 \%$, $30 \%$ and $11-44 \%$, respectively [11]. Burning or shooting pain in the toes or feet is present in $13 \%$ of survivors five years following chemotherapy [12]. However, in patients with cancer, including inpatients in hospice, NP may also be caused by comorbidities, such as diabetes mellitus or alcohol overuse. About $20 \%$ of patients with long term diabetes patients develop painful neuropathy [13]. Patients with alcoholic neuropathy report pain more often when alcohol itself is the cause, and less often when polyneuropathy is caused by thiamine deficiency [14].

The number of patients with NP-RPN increases with cancer progression as there are more factors adversely affecting peripheral nerves. These include steroid-induced diabetes and nutritional deficiencies. Data concerning the prevalence of painful neuropathy in people with advanced cancer are lacking. It is only known that symptoms of peripheral neuropathy in the form of tingling/numbness in hands and/or feet are found in $40 \%$ of hospice patients [15]. The identification and control of etiological factors of NP in hospice patients seems to be important, as it has been demonstrated that NP may have a significantly greater impact on physical, cognitive and social functioning than nociceptive pain $[7,16]$.

$\mathrm{NP}$ is associated with damage to small nerve fibers. It has been demonstrated, however, that pain in painful peripheral neuropathy (not only cancer-related) is often accompanied by disorders of various sensory modalities, including touch, meaning that both small and large fibers were damaged [17].

Compared to small fibers, damage to large sensory fibers is relatively simple to evaluate in a nerve conduction test. It is an objective, comparable, reproducible and readily accessible examination. Additionally, it enables objective assessment of motor fibers. On the other hand, the clinical assessment of small fiber function (quantitative sensation tests) is difficult; the examinations are very time-consuming, poorly standardized and require patients to stay focused for a long time and be fully cooperative. Novel neurophysiological techniques (laser-induced potentials) or skin biopsies are poorly available and not well tolerated.

According to the grading system for NP, proposed by the International Association for the Study of Pain (IASP), the final level of certainty requires confirmation of the lesion or disease of the somatosensory nervous system by objective tests, such as a nerve conduction study. Nevertheless, in practice, neuropathic pain is diagnosed mainly based on medical history and physical examination [18].

The increasing life expectancy of people diagnosed with cancer, including those with advanced disease, is associated with increased prevalence of clinically significant peripheral nerve injury. The signs and symptoms of polyneuropathy may vary depending on the type of damaged nerve fibers. Being aware of their presence and knowing the grade and profile of this damage could help improve the quality of palliative care, particularly with respect to pain control — especially for neuropathic pain and in terms of physiotherapeutic management (e.g., prevention of muscle atrophy, balance disorders, falls) [19-23]. The aim of this study is to evaluate NP-RPN prevalence and its relationship with other symptoms of peripheral neuropathy diagnosed by clinical and neurophysiological examination in hospice in patients with advanced cancer. 


\section{Patients and Methods}

\subsection{Patient Selection}

The study enrolled patients with advanced cancer who were hospitalized in inpatient hospices in Chojnice, Bydgoszcz, Sopot and Gdansk (Poland). The inclusion criteria included age over 18 years and a diagnosis of an advanced cancer. Patients with implanted cardioverter-defibrillators and patients in poor overall condition that prevented informed consent were excluded. A total of 80 patients were enrolled; none refused participation. In four patients, complete clinical and neurophysiological examination could not be undertaken and so 76 records were available for analyses.

\subsection{Methods}

Medical history concerning disease duration, risk factors for neuropathy, reported neuropathic symptoms, used medications and body weight reduction within the past 6 months was collected from all patients. Information about the type of cancer and previous therapy as well as current treatment was derived from the medical records.

NP-RPN was diagnosed based on a medical interview by asking patients about the presence of shooting or burning pain in the feet (or in the feet and hands). This question was based on item 36 of the EORTC (European Organisation for Research and Treatment of Cancer) quality of life questionnaire to assess chemotherapy-induced peripheral neuropathy (QLQ-CIPN20). The severity of symptoms was assessed on a 4-point scale (1-not at all, 2-a little bit, 3-quite a bit, 4-very much) [24]. NP-RPN was diagnosed when the patient reported symptoms with intensity ranging from low to high (2-4).

All patients had their height, weight and BMI (body mass index) measured. The cancer patient performance status was determined using the Karnofsky scale. Cachexia was defined as body weight reduction by over $5 \%$ within 6 months or over $2 \%$ in patients with baseline BMI $<20$, according to the consensus 2011 [25].

Patients were examined for muscle strength (extensors of the hallux and foot) according to the Lovett scale and for the patellar and Achilles reflexes in order to assess motor fiber function.

The sensory examination began from the hallux and proceeded upwards if any abnormalities were found. Various sensory modalities were tested: pain sensation using a disposable sterile Neurotip pin, temperature sensation using Tip-Therm, position sense, vibratory sense using a $128 \mathrm{~Hz}$ tuning fork and touch sensation using a $10 \mathrm{~g}$ monofilament.

The National Cancer Institute (NCI) Common Terminology Criteria for Adverse Events version 4.0 (CTCAE v.4.0) were used for the clinical evaluation of the stage of poly-neuropathy. The NCI-CTCAE is a descriptive terminology which can be utilized for adverse event (AE) reporting. A grading (severity) scale is provided for each AE term. This is a 5 -point scale [26].

All electroneurographic examinations were conducted using standard methods with a Dantec Keypoint device v.2.32 (production year 2014, Natus Manufacturing Limited IDA Business Park Gort, Co. Galway, Ireland). Prior to the examination, skin temperature was controlled on the dorsal aspect of the foot; if lower than 27 degrees Celsius, the foot was warmed. The electrophysiological examination of the sensory nerves included:

- $\quad$ The median and ulnar nerves in the upper extremity (orthodromic method);

- The sural nerve in the lower extremity (antidromic method).

The motor nerve examination included:

- The median and ulnar nerves in the upper extremity;

- The peroneal nerve in the lower extremity.

The electrophysiological examination was conducted using the non-dominant upper extremity. In patients with breast cancer, the test was conducted on the upper extremity contralateral to the site of cancer. The lower extremity was tested on the right side. The motor fiber assessment included terminal latency, conduction velocity and M-wave amplitude. The sensory fiber assessment included conduction velocity and reflex amplitude. 
Widely accepted criteria for identification of abnormalities were used [27]. Polyneuropathy in electroneurography (ENG) was defined in accordance with the recommendations of the American Academy of Neurology (AAN) [28]. Polyneuropathy was diagnosed in case of an abnormality of any attribute of nerve conduction in the sural nerve and at least one other nerve.

\subsection{Ethical Approval}

The study protocol was approved by the Ethics Committee of the Nicolaus Copernicus University in Torun, Collegium Medicum in Bydgoszcz, Poland (KB 268/2015 dated 21 April 2015 with amendment dated 20 October 2015 and 25 September 2018). All patients expressed written consent to the participation in the study.

\subsection{Statistical Analyses}

Statistical analyses were conducted using a licensed version of the statistical software STATISTICA, version 13.1 (data analysis software), developed by Tibco Software, Inc (2017), Palo Alto, CA, USA. The null-hypothesis for statistical analyses in this study was that patients with and without neuropathic pain related do not differ in relation to values of parameters analyzed, both clinical and electrophysiological. The sample size was calculated post hoc with the assumption that parameters studied will differ between groups analyzed by $20 \%$ with $25 \%$ of standard deviation (un-paired variables). We assumed also the use of the Student's $t$-test and the Mann-Whitney U-test, an alpha of 0.05 , a beta of 0.10 (power of analysis at least 90\%). However, such analysis design required inclusion at least 522 patients.

The normal distribution of the study variables was checked using the KolmogorovSmirnov test. The statistical significance level was set at a $p$-value of $<0.05$. The results were presented as the mean \pm standard deviation, or $n, \%$. The statistical significance of the differences between the groups was verified using the Student's $t$-test and the Mann-Whitney U-test for quantitative variables (for parametric and non-parametric tests, respectively), and the Fisher's exact test was used for categorical variables. Rank Spearman correlations were calculated.

\section{Results}

Of the 76 patients included in the final analysis, NP-RPN was found in 29\% (Table 1). Electrophysiological peripheral neuropathy according to the AAN was found in $79 \%$ of the patients. Both disorders overlapped in $26 \%$ of the patients, but the relationship between the presence of NP-RPN and the diagnosis of neuropathy according to the AAN criteria was not statistically significant (Table 2 ). In the group with NP-RPN, $18 \%$ of the patients reported pain of greater intensity (grade 3 and 4 ).

The clinical characteristics of patients with and without NP-RPN differed in relation to opioid use but without statistical significance (Table 1). That is why the neurological and neurophysiological examinations were performed to determine whether their results discriminate between patients with and without NP-RPN (Tables 3 and 4).

However, there were no statistically significant differences in the clinical and electrophysiological parameters between the analyzed sub-groups (Table 3 andTable 4). The only exception was that patients with NP-RPN more frequently presented factors that made the ENG examination more difficult to perform, more often had touch sensation disturbances, and the diagnosis of sensory neuropathy according to the NCI criteria was more prevalent (Table 3). Sensory neuropathy according to the NCI was found in all NP-RPN patients, and one half of the patients without NP-RPN met the diagnostic criteria (Table 3). It was assumed that NP-RPN might be a biomarker of peripheral neuropathy, which could make it possible to avoid bothersome electrophysiological testing. However, its diagnostic test parameters failed to achieve satisfactory values (parameter, 95\% CI): accuracy: 64.5, 52.7-75.1\%; sensitivity: 44.9, 30.7-59.8\%, specificity: 100, 87.2-100.0\%; positive predictive 
value (PPV): 100\%; negative predictive value (NPV): 50, 43.7-56.3\%; and likelihood ratio (LR) for a negative result: $0.6,0.4-0.7$.

Table 1. Clinical characteristics of hospice patients without and with NP-RPN.

\begin{tabular}{|c|c|c|c|}
\hline Parameter & $\begin{array}{c}\text { Patients without } \\
\text { NP-RPN } \\
(\mathrm{n}=54,71 \%)\end{array}$ & $\begin{array}{l}\text { Patients with } \\
\text { NP-RPN } \\
(n=22,29 \%)\end{array}$ & $p$ \\
\hline Male/female & $27(50.0 \%) / 27(50.0 \%)$ & $9(40.9 \%) / 13(59.1 \%)$ & 0.478 \\
\hline Age (years) & $69.81 \pm 12.75$ & $71.41 \pm 9.91$ & 0.601 \\
\hline Survival (days) & $228.41 \pm 306.10$ & $173.68 \pm 277.36$ & 0.476 \\
\hline $\begin{array}{l}\text { Disease duration } \\
\quad \text { (months) }\end{array}$ & $31.98 \pm 34.41$ & $42.38 \pm 56.32$ & 0.344 \\
\hline Anticonvulsants (n, \%) & $15(27.78 \%)$ & $6(27.27 \%)$ & 0.965 \\
\hline Antidepressants (n, \%) & $13(24.01 \%)$ & $7(31.82 \%)$ & 0.487 \\
\hline Opioids (n, \%) & $35(64.81 \%)$ & $19(86.36 \%)$ & 0.062 \\
\hline Previous $\mathrm{CHTH}$ & $23(42.59)$ & $12(54.55)$ & 0.614 \\
\hline Diabetes & $11(35.19)$ & $2(9.09)$ & 0.365 \\
\hline $\begin{array}{l}\text { Alcohol dependence } \\
\text { syndrome }\end{array}$ & $6(11.11)$ & $2(9.79)$ & 0.867 \\
\hline Other diseases & $35(64.81)$ & 17 (77.27) & 0.289 \\
\hline $\mathrm{BMI}\left(\mathrm{kg} / \mathrm{m}^{2}\right)$ & $22.45 \pm 4.54$ & $22.28 \pm 4.51$ & 0.885 \\
\hline Cancer cachexia & $31(57.4 \%)$ & $15(68.2 \%)$ & 0.494 \\
\hline Weight loss (\%) & 16.22 & 15.06 & 0.834 \\
\hline $\begin{array}{l}\text { Actual to ideal body } \\
\text { mass ratio }(\%)\end{array}$ & $101.47 \pm 19.69$ & $101.48 \pm 21.20$ & 0.999 \\
\hline Body mass deficit & $27(50.00 \%)$ & $10(45.45 \%)$ & 0.724 \\
\hline Karnofsky score & $56.67 \pm 16.02$ & $64.55 \pm 15.65$ & 0.054 \\
\hline
\end{tabular}

Legend: NP-RPN—neuropathic pain related to peripheral neuropathy; $\mathrm{n}$-number of patients; $\mathrm{CHTH}-$ chemotherapy; BMI—body mass index.

Table 2. The relationships between clinically reported peripheral neuropathy and presence of abnormalities in electrophysiological examination.

\begin{tabular}{|c|c|c|c|c|}
\hline & & \multicolumn{3}{|c|}{ Clinically Reported Painful Peripheral Neuropathy } \\
\hline & & No & Yes & Total \\
\hline \multirow{2}{*}{$\begin{array}{l}\text { Electrophysiological studies consistent } \\
\text { with peripheral neuropathy }(n, \%)\end{array}$} & no & $14(18.42)$ & $2(2.63)$ & $16(21.05)$ \\
\hline & yes & $40(52.63)$ & $20(26.32)$ & $60(78.95)$ \\
\hline
\end{tabular}

Fisher's exact test-0.1294.

Table 3. Alterations in neurological examination in patients without and with NP-RPN.

\begin{tabular}{cccc}
\hline Parameter & $\begin{array}{c}\text { Patients without } \\
\text { NP-RPN } \\
(\mathbf{n}=\mathbf{5 4}, \mathbf{7 1} \%)\end{array}$ & $\begin{array}{c}\text { Patients with } \\
\text { NP-RPN } \\
(\mathbf{n}=\mathbf{2 2 ,} \mathbf{2 9} \%)\end{array}$ & $p$ \\
\hline $\begin{array}{c}\text { No other (non-neuropathic) abnormalities in } \\
\text { neurological examination (n, \%) }\end{array}$ & $34(63.0)$ & $17(77.3)$ & 0.183 \\
\hline Touch sensation disorders R & $6(11.1)$ & $7(24.1)$ & 0.022 \\
\hline Vibratory sense disorders R & $25(46.3)$ & $11(37.9)$ & 0.641 \\
\hline
\end{tabular}


Table 3. Cont.

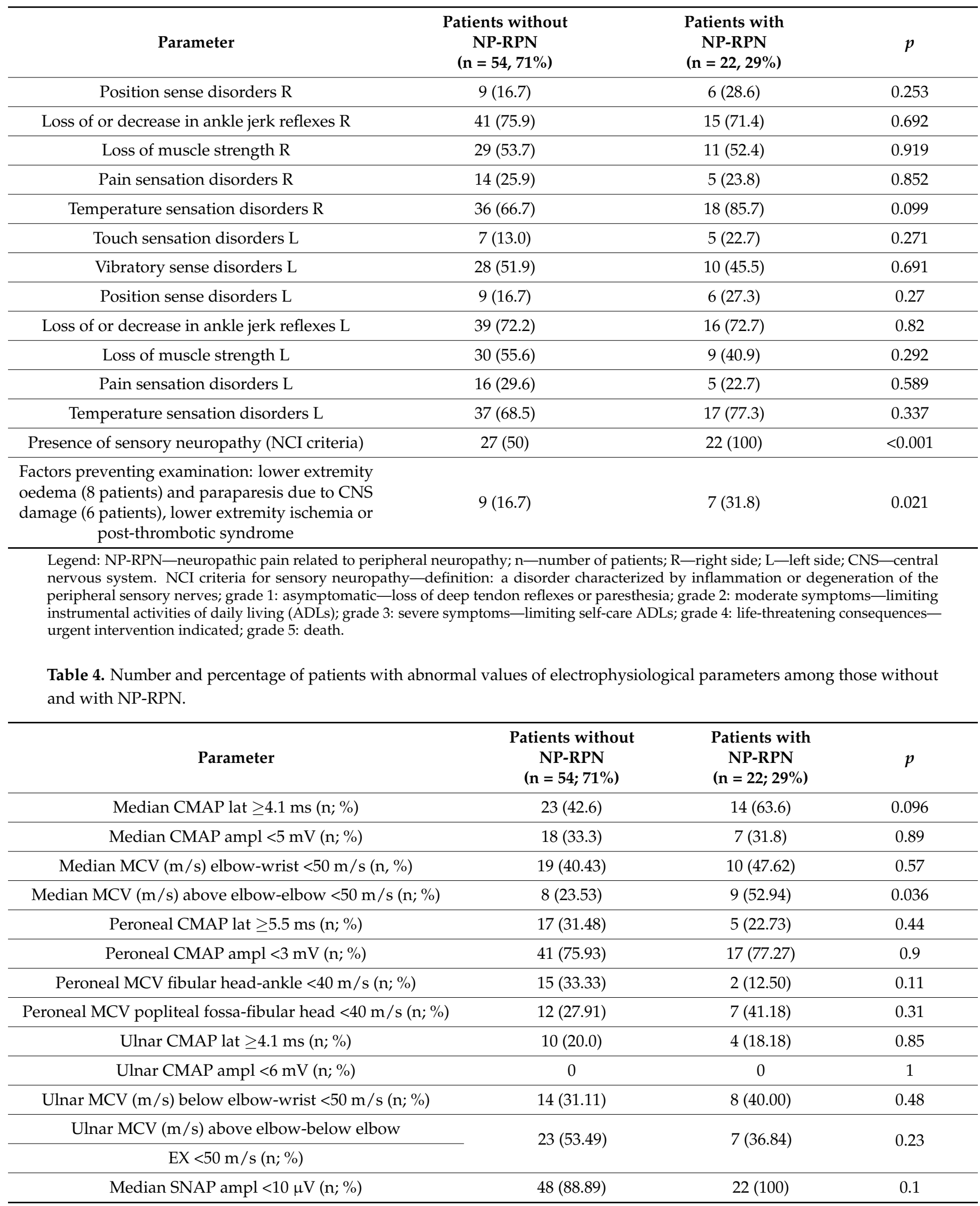


Table 4. Cont.

\begin{tabular}{|c|c|c|c|}
\hline Parameter & $\begin{array}{c}\text { Patients without } \\
\text { NP-RPN } \\
(\mathrm{n}=54 ; 71 \%)\end{array}$ & $\begin{array}{c}\text { Patients with } \\
\text { NP-RPN } \\
(n=22 ; 29 \%)\end{array}$ & $p$ \\
\hline Median SCV <50 m/s (n; \%) & $47(87.04)$ & $20(90.91)$ & 0.63 \\
\hline Sural SNAP ampl <7 $\mu \mathrm{V}$ (n; \%) & $44(81.48)$ & $18(81.82)$ & 0.97 \\
\hline Sural SCV <40 m/s (n; \%) & $37(68.58)$ & $11(52.38)$ & 0.19 \\
\hline Ulnar SNAP ampl $<6 \mu \mathrm{V}(\mathrm{n} ; \%)$ & $45(83.33)$ & $14(63.64)$ & 0.06 \\
\hline Ulnar SCV <50 m/s (n; \%) & $31(57.41)$ & $9(40.91)$ & 0.19 \\
\hline
\end{tabular}

Legend: NP-RPN—neuropathic pain related to peripheral neuropathy; n-number of patients; CMAP—compound muscle action potential; lat—distal latency; ampl—amplitude; MCV—motor conduction velocity; SNAP—sensory nerve action potential; SCV—sensory conduction velocity.

The severity of NP-RPN correlated with the clinically assessed severity of sensory neuropathy diagnosed according to the NCI-CTCAE v.4.0 both in the entire study group and in the sub-group of patients with NP-RPN (Table 5). However, the severity of NP-RPN did not correlate with the intensity of the clinical signs of motor neuropathy, even though a negative correlation with Karnofsky score was found in the entire group of hospice patients (Table 5). The severity of NP-RPN correlated only with less important ENG parameters, such as left peroneal nerve conduction velocity as well as the latency and amplitude of the median nerve sensory fibers and did not correlate with the diagnosis of peripheral neuropathy according to the AAN (Table 5).

Table 5. Selected Spearman rank correlations between severity of neuropathic pain related to peripheral neuropathy (1-4 quantitative score) and the presence of abnormalities in neurological examination and neurophysiological parameters.

\begin{tabular}{|c|c|c|c|c|}
\hline \multirow[t]{2}{*}{ Correlation between NP Severity and: } & \multicolumn{2}{|c|}{$\begin{array}{l}\text { Whole Study Group } \\
\quad(\mathrm{n}=76)\end{array}$} & \multicolumn{2}{|c|}{$\begin{array}{l}\text { Patients with NP-RPN } \\
\qquad(\mathrm{n}=29)\end{array}$} \\
\hline & R Spearman & $p$ & R Spearman & $p$ \\
\hline Karnofsky score & -0.23 & 0.049 & -0.02 & 0.94 \\
\hline Grade of sensory neuropathy according to NCI criteria & 0.62 & $<0.001$ & 0.78 & $<0.001$ \\
\hline $\begin{array}{l}\text { Grade of motor neuropathy } \\
\text { according to NCI criteria }\end{array}$ & -0.06 & 0.61 & 0.14 & 0.57 \\
\hline Temperature sensation disorders $\mathrm{L}$ & 0.14 & 0.222 & 0.38 & 0.085 \\
\hline Pain sensation disorders $\mathrm{L}$ & -0.05 & 0.643 & 0.09 & 0.702 \\
\hline Loss of muscle strength L & -0.09 & 0.421 & 0.29 & 0.205 \\
\hline Loss of or decrease in ankle jerk reflexes L & 0.07 & 0.547 & 0.48 & 0.027 \\
\hline Vibratory sense disorders L & -0.04 & 0.721 & 0.04 & 0.857 \\
\hline Position sense disorders L & 0.15 & 0.194 & 0.23 & 0.311 \\
\hline Touch sensation disorders L & 0.14 & 0.232 & 0.12 & 0.61 \\
\hline Median CMAP lat (ms) & 0.21 & 0.069 & 0.33 & 0.133 \\
\hline Median CMAP ampl (mV) & 0.06 & 0.61 & -0.02 & 0.945 \\
\hline Median MCV (m/s) elbow-wrist & 0.03 & 0.801 & 0.2 & 0.386 \\
\hline Median MCV (m/s) above elbow-elbow & -0.2 & 0.152 & 0.27 & 0.298 \\
\hline Peroneal CMAP lat (ms) & -0.07 & 0.569 & -0.2 & 0.382 \\
\hline Peroneal CMAP ampl $(\mathrm{mV})$ & -0.11 & 0.343 & -0.3 & 0.176 \\
\hline Peroneal MCV (m/s) fibular head-ankle & 0.2 & 0.115 & -0.66 & 0.005 \\
\hline Peroneal MCV (m/s) popliteal fossa-fibular head & 0 & 0.993 & -0.14 & 0.591 \\
\hline Ulnar CMAP lat (ms) & -0.01 & 0.962 & -0.21 & 0.351 \\
\hline Ulnar CMAP ampl (mV) & 0.09 & 0.457 & -0.18 & 0.413 \\
\hline Ulnar MCV (m/s) below elbow-wrist & -0.12 & 0.357 & -0.33 & 0.153 \\
\hline Ulnar MCV (m/s) above elbow-below elbow & 0.25 & 0.048 & -0.15 & 0.549 \\
\hline Median SNAP ampl $(\mu \mathrm{V})$ & -0.12 & 0.289 & -0.46 & 0.03 \\
\hline Median SCV (m/s) & -0.06 & 0.587 & -0.38 & 0.08 \\
\hline Ulnar SNAP ampl $(\mu \mathrm{V})$ & 0 & 0.98 & -0.19 & 0.394 \\
\hline
\end{tabular}


Table 5. Cont.

\begin{tabular}{|c|c|c|c|c|}
\hline \multirow[t]{2}{*}{ Correlation between NP Severity and: } & \multicolumn{2}{|c|}{$\begin{array}{l}\text { Whole Study Group } \\
\qquad(\mathrm{n}=76)\end{array}$} & \multicolumn{2}{|c|}{$\begin{array}{c}\text { Patients with NP-RPN } \\
\text { (n= 29) }\end{array}$} \\
\hline & R Spearman & $p$ & R Spearman & $p$ \\
\hline Ulnar SCV (m/s) & 0.12 & 0.314 & -0.02 & 0.944 \\
\hline Sural SNAP ampl $(\mu \mathrm{V})$ & 0.1 & 0.386 & -0.06 & 0.794 \\
\hline Sural SCV $(\mathrm{m} / \mathrm{s})$ & 0.09 & 0.443 & -0.06 & 0.781 \\
\hline Neuropathy according to AAN & 0.03 & 0.817 & 0.33 & 0.135 \\
\hline Conduction block & 0.14 & 0.594 & 0.5 & 0.5 \\
\hline
\end{tabular}

Legend: NP-RPN—neuropathic pain related to peripheral neuropathy; $n$-number of patients; NCI criteria for sensory neuropathy-grade 1: asymptomatic - loss of deep tendon reflexes or paresthesia; grade 2: moderate symptoms-limiting instrumental activities of daily living (ADLs); grade 3: severe symptoms-limiting self-care ADLs; grade 4: life-threatening consequences-urgent intervention indicated; grade 5: death; NCI criteria for motor neuropathy - grade 1: asymptomatic - clinical or diagnostic observations only; intervention not indicated; grade 2: moderate symptoms-limiting instrumental ADLs; grade 3: severe symptoms-limiting self-care ADLs, assistive device indicated; grade 4: life-threatening consequences—urgent intervention indicated; grade 5: death; L-left side; CMAP—compound muscle action potential; lat—distal latency; ampl—amplitude; $\mathrm{MCV}$-motor conduction velocity; SNAP—sensory nerve action potential; SCV—sensory conduction velocity; AAN-American Academy of Neurology.

\section{Discussion}

The present study revealed that NP-RPN occurs in nearly $30 \%$ and peripheral neuropathy in nearly $80 \%$ of hospice in patients with advanced cancer. Interestingly, NP-RPN was not more common in patients after chemotherapy or in patients with diabetes or a history of excessive alcohol use, although this could result from a small sample size (Table 1). It is difficult to compare the results regarding NP-RPN with observations from other studies performed among hospice patients as other authors usually assessed the prevalence of sensory neuropathy (with or without pain) or neuropathic pain without specifying whether it was NP-RPN. In this context, Tofthagen et al. [15] noted neuropathic symptoms, such as numbness and tingling in the lower and/or upper extremities, in $40 \%$ of hospice patients, although pain was not analyzed. An analysis of 29 prospective studies demonstrated that NP occurs in 25.4-39.3\% of palliative care patients with cancer pain, whereas the respective percentage among all palliative patients in Japan was 18.6\% [6,8]. In another Japanese study conducted among terminally ill patients with cancer admitted to general wards, the percentage was $30.6 \%$ (6.5\% of these patients reported no pain) [29]. Yet another study performed among patients of whom $70 \%$ had advanced cancer showed that neuropathic pain occurred in $36 \%$ of patients with cancer pain [7].

Compared to other patient groups, the NP-RPN rate in this study was similar to the rates reported for diabetic patients (21-60\%) [30] and lower than the rate of painful polyneuropathy found in patients with polyneuropathy of various etiologies [31].

It is surprising that NP-RPN severity was not found to be correlated with other clinical signs (except for the performance status according to the Karnofsky scale) and nerve conduction studies (except for less significant parameters; Table 5). This might mean that, on the one hand, the small fiber-related positive symptoms in the form of NP do not occur simultaneously with large fiber damage (which can be diagnosed by ENG and clinical examination; Tables 3 and 4 ) and, on the other hand, that those symptoms are not correlated with small fiber-related negative symptoms in the form of decreased sensitivity to pain or temperature on the clinical examination (Table 3 ).

Surprisingly, there is significant percentage of patients with disturbances of various sensory modalities, even though only one half of the patients had undergone previous chemotherapy (Tables 3 and 4). Chemotherapy is considered one of the more significant causes of neurotoxicity. Recent studies have put the prevalence of chemotherapy-induced peripheral neuropathy (CIPN) at approximately $68.1 \%$ when measured in the first month after chemotherapy, $60.0 \%$ at 3 months, and $30.0 \%$ at and after 6 months [32]. Around 30\% of patients will still have CIPN one year, or more, after finishing chemotherapy [33,34]. Up to $40 \%$ of individuals who receive neurotoxic chemotherapy develop chronic painful CIPN. The highest rates of painful polyneuropathy are observed in bortezomib-treated patients [11]. Among patients without pre-existing neuropathy, NP-RPN at one year after 
therapy was observed in $35.1 \%$ of patients treated with docetaxel and in $31.3 \%$ of patients treated with oxaliplatin. Questionnaire-based signs of polyneuropathy, irrespective of pain, were found in $63.6 \%$ of patients from the oxaliplatin group and in $44.8 \%$ of patients from the docetaxel group [35]. Apparently, the greater prevalence of neuropathy in the hospice patients evaluated in this study as compared with other studies was related to the impact of cancer itself $[36,37]$. Other explanations for such considerable prevalence of poly-neuropathy are also possible, including complications after therapy, comorbidities, cachexia or nutritional deficiencies.

Interestingly, in our study patients with NP-RPN received opioids with a borderline greater frequency than patients without this type of pain, although the percentage of patients treated with these drugs was almost twice as high as the percentage of patients treated with anticonvulsants and antidepressants, where the rates were similar in both NP-RPN and non-NP-RPN groups (Table 1). This might mean that NP-RPN patients had in fact greater intensity of other types of pain (nociceptive) or that NP was not properly diagnosed and treated. This greater use of opioids cannot be attributed to more advanced disease or longer disease duration as neither survival nor disease duration differed between the groups (Table 1). These observations are not, however, inconsistent with the literature data. Although antidepressants and anticonvulsants are first-choice drugs in NP-RPN, particularly in patients with $\mathrm{CHTH}$, it should be noted that their use is still insufficient [38,39]. In one study with over 2000 patients, fewer than half of patients with cancer NP were treated with adjuvant analgesics [7]. In another study with almost 900 patients, only $8 \%$ received adjuvant pain treatment [40]. In this study, the respective percentage was higher and reached $1 / 3$ of patients (Table 1 ). Using anticonvulsants and antidepressants can be challenging among elderly especially in context of high presence of polypharmacy and its complications such as falls and delirium [41-43]

Our study, even if only preliminary, allowed us to make very important observation that clinically apparent NP-RPN represents only a sub-group of all people with electrophysiologically defined peripheral neuropathy (Table 2).

The current observations regarding neuropathy in hospice patients may be significant for developing management strategies, especially as the life expectancy of cancer patients is increasing and one should expect that the number of patients with this problem will increase as well [44]. Both NP-RPN and polyneuropathy, which may remain undiagnosed, pose problems. It was unfortunately impossible to confirm that NP-RPN may be a good marker of polyneuropathy in hospice patients. Nonetheless, the present study shows that patient performance deteriorates with the severity of painful neuropathy (negative correlation between the Karnofsky score and the severity of neuropathic pain; Table 5). This warrants the search for more effective methods to manage neuropathic pain. Other symptoms of polyneuropathy, such as sensory (especially proprioceptive) disorders, and motor neuropathy seen on nerve conduction studies (although the interpretation is highly challenging due to concomitant cachexia and sarcopenia), prompt consideration of patient rehabilitation strategy, especially during the COVID-19 pandemic, as a potential cause of polyneuropathy overlapping [45].

The results of the present study reveal not only that intervention is required for the loss of muscle strength, but also that attention in palliative care should be directed to the neuropathic component, which might affect patient functioning. Physiotherapists should therefore focus on teaching patients to visually correct the position of individual parts of the body in space, which might decrease the number of falls [46-48]. Further studies should also address the issue of the stage of cancer at which potential risk factors of painful neuropathy, such as $\mathrm{CHTH}$, diabetes or alcoholism, start to be less significant in polyneuropathy development than cancer itself.

\section{Limitations of the Study}

The greatest limitation in this study was the inability to objectively assess small fibers function, which is the main reason of neuropathic pain. The second limitation of our study 
was the inclusion of an insufficient number of patients, which affected both the power and statistical significance of the observed differences. The insufficient number of patients enclosed the post-hoc calculated power of the analyses, which did not reach statistical significance $(p<0.05)$ and amounted to $0.12-0.28$, making it impossible to accept a null hypothesis when the $p$-value was $\geq 0.05$. The third study limitation was that we had no possibility to determine the type and doses of previous chemotherapy, and perhaps if treatment with drugs of low neurotoxicity had been excluded, the effect of chemotherapy on the occurrence of neuropathic pain might have been confirmed. The fourth limitation was related to the use of norms of ENG parameters validated for patients with neurological disorder but not for hospice patients (to our best knowledge not available until now). Moreover, it was impossible to complete data about the type and doses of analgesics, which might have otherwise enabled analysis of treatment efficacy. That is why it is necessary to design a multicenter study to recruit more patients.

\section{Conclusions}

In this preliminary single center study, NP-RPN was reported in about $30 \%$ of hospice patients. However, its diagnosis did not reflect the greater prevalence of motor and sensory abnormalities found in neurological and electrophysiological examinations. NP-RPN did not achieve sufficient values of diagnostic test parameters, and therefore the diagnosis of NP-RPN cannot be used as a biomarker of polyneuropathy in hospice patients.

Author Contributions: Conceptualization, J.D.-G. and M.K.; methodology, J.D.-G. and M.K.; investigation, J.D.-G.; statistical analysis, J.B.; critical analysis of the results, J.B., J.D.-G., M.K., A.P., D.C.; data curation, J.B.; writing-original draft preparation, J.D.-G., J.B.; writing-review and editing, J.D.-G., M.K., A.P., D.C., J.B.; All authors have read and agreed to the published version of the manuscript.

Funding: This research received no external funding. The APC was funded by Nicolaus Copernicus Universisty in Torun Collegium Medicum in Bydgoszcz, Poland.

Institutional Review Board Statement: The study was conducted according to the guidelines of the Declaration of Helsinki, and approved by the Ethics Committee of the Nicolaus Copernicus University in Torun, Collegium Medicum in Bydgoszcz, Poland (KB 268/2015 dated 21 April 2015 with amendment dated 20 October 2015 and 25 September 2018).

Informed Consent Statement: Informed consent was obtained from all subjects involved in the study.

Conflicts of Interest: The authors declare no conflict of interest.

\section{References}

1. Treede, R.-D.; Jensen, T.S.; Campbell, J.N.; Cruccu, G.; Dostrovsky, J.O.; Griffin, J.W.; Hansson, P.; Hughes, R.; Nurmikko, T.; Serra, J. Neuropathic pain: Redefinition and a grading system for clinical and research purposes. Neurology 2008, 70, $1630-1635$. [CrossRef] [PubMed]

2. Scholz, J.; Finnerup, N.B.; Attal, N.; Aziz, Q.; Baron, R.; Bennett, M.I.; Benoliel, R.I.; Cohen, M.; Cruccu, G.; Davis, K.D.; et al. Classification Committee of the Neuropathic Pain Special Interest Group (NeuPSIG). The IASP classification of chronic pain for ICD-11: Chronic neuropathic pain. Pain 2019, 160, 53-59. [CrossRef]

3. Hecke, O.V.; Austin, S.K.; Khan, R.A.; Smith, B.H.; Torrance, N. Neuropathic pain in the general population: A systematic review of epidemiological studies. Pain 2014, 155, 654-662. [CrossRef]

4. Gierthmühlen, J.; Baron, R. Neuropathic Pain. Semin. Neurol. 2016, 36, 462-468. [CrossRef] [PubMed]

5. Bennett, M.I.; Rayment, C.; Hjermstad, M.; Aass, N.; Caraceni, A.; Kaasa, S. Prevalence and aetiology of neuropathic pain in cancer patients: A systematic review. Pain 2012, 153, 359-365. [CrossRef]

6. Roberto, A.; Deandrea, S.; Greco, M.T.; Corli, O.; Negri, E.; Pizzuto, M.; Ruggeri, F. Prevalence of Neuropathic Pain in Cancer Patients: Pooled Estimates From a Systematic Review of Published Literature and Results From a Survey Conducted in 50 Italian Palliative Care Centers. J. Pain Symptom Manag. 2016, 51, 1091-1102. [CrossRef] [PubMed]

7. Oh, S.Y.; Shin, S.W.; Koh, S.-J.; Bae, S.B.; Chang, H.; Kim, J.H.; Kim, H.J.; Hong, Y.S.; Park, K.U.; Park, J.; et al. Multicenter, cross-sectional observational study of the impact of neuropathic pain on quality of life in cancer patients. Support. Care Cancer 2017, 25, 3759-3767. [CrossRef] [PubMed]

8. Harada, S.; Tamura, F.; Ota, S. The Prevalence of Neuropathic Pain in Terminally Ill Patients With Cancer Admitted to a Palliative Care Unit: A Prospective Observational Study. Am. J. Hosp. Palliat. Med. 2016, 33, 594-598. [CrossRef] [PubMed] 
9. $\quad$ Pusztai, L.; Mendoza, T.R.; Reuben, J.M.; Martinez, M.M.; Willey, J.S.; Lara, J.; Syed, A.; Fritsche, H.A.; Bruera, E.; Booser, D.; et al. Changes in plasma levels of inflammatory cytokines in response to paclitaxel chemotherapy. Cytokine 2004, 25, 94-102. [CrossRef]

10. Yoon, S.Y.; Oh, J. Neuropathic cancer pain: Prevalence, pathophysiology, and management. Korean J. Intern. Med. 2018, 33, 1058-1069. [CrossRef]

11. Kanzawa-Lee, G.A.; Knoerl, R.; Donohoe, C.; Bridges, C.M.; Smith, E.M. Mechanisms, Predictors, and Challenges in Assessing and Managing Painful Chemotherapy-Induced Peripheral Neuropathy. Semin. Oncol. Nurs. 2019, 35, 253-260. [CrossRef]

12. Beijers, A.J.; Mols, F.; Tjan-Heijnen, V.C.; Faber, C.G.; van de Poll-Franse, L.V.; Vreugdenhil, G. Peripheral neuropathy in colorectal cancer survivors: The influence of oxaliplatin administration. Results from the population-based PROFILES registry. Acta Oncol. 2015, 54, 463-469. [CrossRef] [PubMed]

13. Sloan, G.; Shillo, P.; Selvarajah, D.; Wu, J.; Wilkinson, I.D.; Tracey, I.; Anand, P.; Tesfaye, S. A new look at painful diabetic neuropathy. Diabetes Res. Clin. Pract. 2018, 144, 177-191. [CrossRef] [PubMed]

14. Koike, H.; Iijima, M.; Sugiura, M.; Mori, K.; Hattori, N.; Ito, H.; Hirayama, M.; Sobue, G. Alcoholic neuropathy is clinicopathologically distinct from thiamine-deficiency neuropathy. Ann. Neurol. 2003, 54, 19-29. [CrossRef] [PubMed]

15. Tofthagen, C.; Visovsky, C.; Dominic, S.; McMillan, S. Neuropathic symptoms, physical and emotional well-being, and quality of life at the end of life. Support. Care Cancer 2019, 27, 3357-3364. [CrossRef]

16. Rayment, C.; Hjermstad, M.J.; Aass, N.; Kaasa, S.; Caraceni, A.; Strasser, F.; Heitzer, E.; Fainsinger, R.; Bennett, M.I.; European Palliative Care Research Collaborative (EPCRC). Neuropathic cancer pain: Prevalence, severity, analgesics and impact from the European Palliative Care Research Collaborative-Computerised Symptom Assessment study. Palliat. Med. 2013, 27, 714-721. [CrossRef]

17. Baron, R.; Maier, C.; Attal, N.; Binder, A.; Bouhassira, D.; Cruccu, G.; Finnerup, N.B.; Haanpää, M.; Hansson, P.; Hüllemann, P.; et al. German Neuropathic Pain Research Network (DFNS), and the EUROPAIN, and NEUROPAIN consortia. Peripheral neuropathic pain: A mechanism-related organizing principle based on sensory profiles. Pain 2017, 158, 261-272. [CrossRef]

18. Finnerup, N.B.; Haroutounian, S.; Kamerman, P.; Baron, R.; Bennett, D.L.; Bouhassira, D.; Cruccu, G.; Freeman, R.; Hansson, P.; Nurmikko, T.; et al. Neuropathic pain: An updated grading system for research and clinical practice. Pain 2016, 157, $1599-1606$. [CrossRef]

19. Marshall, T.F.; Zipp, G.P.; Battaglia, F.; Moss, R.; Bryan, S. Chemotherapy-induced-peripheral neuropathy, gait and fall-risk in older adults following cancer treatment. J. Cancer Res. Pract. 2017, 4, 134-138. [CrossRef]

20. Monfort, S.M.; Pan, X.; Patrick, R. Natural history of postural instability in breast cancer patients treated with taxane-based chemotherapy: A pilot study. Gait Posture 2016, 48, 237-242. [CrossRef] [PubMed]

21. Kneis, S.; Wehrle, A.; Freyler, K.; Lehmann, K.; Rudolphi, B.; Hildenbrand, B.; Bartsch, H.H.; Bertz, H.; Gollhofer, A.; Ritzmann, R. Balance impairment and neuromuscular changes in breast cancer patients with chemotherapy-induced peripheral neuropathy. Clin. Neurophysiol. 2016, 127, 1481-1490. [CrossRef] [PubMed]

22. Monfort, S.M.; Pan, X.; Loprinzi, C.L.; Lustberg, M.B.; Chaudhari, A.M. Exploring the Roles of Central and Peripheral Nervous System Function in Gait Stability: Preliminary Insights from Cancer Survivors. Gait Posture 2019, 71, 62-68. [CrossRef]

23. Monfort, S.M.; Pan, X.; Patrick, R. Gait, Balance, and Patient-Reported Outcomes during Taxane-Based Chemotherapy in Early Stage Breast Cancer Patients. Breast Cancer Res. Treat. 2017, 164, 69-77. [CrossRef] [PubMed]

24. Postma, T.J.; Aaronson, N.K.; Heimans, J.J.; Muller, M.J.; Hildebrand, J.G. The development of an EORTC quality of life questionnaire to assess chemotherapy-induced peripheral neuropathy: The QLQ-CIPN20. Eur. J. Cancer 2005, 41, 1135-1139. [CrossRef] [PubMed]

25. Fearon, K.; Strasser, F.; Anker, S.D.; Bosaeus, I.; Bruera, E. Definition and classification of cancer cachexia: An international consensus. Lancet Oncol. 2011, 12, 489-495. [CrossRef]

26. U.S. Department of Health and Human Services National Institutes of Health National Cancer Institute Common Terminology Criteria for Adverse Events (CTCAE). Available online: https:/ / evs.nci.nih.gov/ftp1/CTCAE/CTCAE_4.03/Archive/CTCAE_4. 0_2009-05-29_QuickReference_8.5x11.pdf (accessed on 28 May 2009).

27. Kimura, J. Electrodiagnosis in Diseases of Nerve and Muscle, Principles and Practice; Oxford University Press: Oxford, UK, 2001; pp. 91-166.

28. England, J.D.; Gronseth, G.S.; Franklin, G.; Miller, R.G.; Asbury, A.K.; Carter, G.T.; Cohen, J.A.; Fisher, M.A.; Howard, J.F.; Kinsella, L.J.; et al. Distal symmetric polyneuropathy: A definition for clinical research: Report of the American Academy of Neurology, the American Association of Electrodiagnostic Medicine, and the American Academy of Physical Medicine and Rehabilitation. Neurology 2005, 64, 199-207. [CrossRef]

29. Yanaizumi, R.; Nagamine, Y.; Harada, S.; Kojima, K.; Tazawa, T.; Goto, T. Prevalence of neuropathic pain in terminally ill patients with cancer admitted to a general ward: A prospective observational study. J. Int. Med. Res. 2021, 49, 1-10. [CrossRef]

30. Abbott, C.A.; Malik, R.A.; van Ross, E.R.E.; Kulkarni, J.; Boulton, A.J. Prevalence and characteristics of painful diabetic neuropathy in a large community-based diabetic population in the U.K. Diabetes Care 2011, 34, 2220-2224. [CrossRef] [PubMed]

31. Girach, A.; Julian, T.H.; Varrassi, G.; Paladini, A.; Vadalouka, A.; Zis, P. Quality of Life in Painful Peripheral Neuropathies: A Systematic Review. Pain Res. Manag. 2019, 2019, 2091960. [CrossRef]

32. Zajączkowska, R.; Kocot-Kepska, M.; Leppert, W.; Wrzosek, A.; Mika, J.; Wordliczek, J. Mechanisms of Chemotherapy-Induced Peripheral Neuropathy. Int. J. Mol. Sci. 2019, 20, 1451. [CrossRef]

33. Colvin, L.A. Chemotherapy-induced peripheral neuropathy: Where are we now? Pain 2019, 160 (Suppl. S1), 1-10. [CrossRef] 
34. Staff, N.P.; Grisold, A.; Grisold, W.; Windebank, A.J. Chemotherapy-induced peripheral neuropathy: A current review. Ann. Neurol. 2017, 81, 772-781. [CrossRef] [PubMed]

35. Ventzel, L.; Jensen, A.B.; Jensen, A.R.; Jensen, T.S.; Finnerup, N.B. Chemotherapy-induced pain and neuropathy: A prospective study in patients treated with adjuvant oxaliplatin or docetaxel. Pain 2016, 157, 560-568. [CrossRef]

36. Boyette-Davis, J.; Eng, C.; Wang, X.S.; Cleeland, C.S.; Wendelschafer-Crabb, G.; Kennedy, W.R.; Simone, D.A.; Zhang, H.; Dougherty, P.M. Subclinical Peripheral Neuropathy Is a Common Finding in Colorectal Cancer Patients Prior to Chemotherapy. Clin. Cancer Res. 2012, 18, 3180-3187. [CrossRef]

37. Hundsberger, T.; Omlin, A.; Haeqele-Link, S.; Vehoff, J.; Strasser, F. Autonomic. dysfunction in cancer cachexia coincides with large fiber polyneuropathy. J. Pain Symptom. Manag. 2014, 48, 611-618. [CrossRef]

38. Loprinzi, C.L.; Lacchetti, C.; Bleeker, J.; Cavaletti, G.; Chauhan, C.; Hertz, D.H.; Kelley, M.R.; Lavino, A.; Lustberg, M.B.; Paice, J.A.; et al. Prevention and Management of Chemotherapy-Induced Peripheral Neuropathy in Survivors of Adult Cancers: ASCO Guideline Update. J. Clin. Oncol. 2020, 38, 3325-3348. [CrossRef] [PubMed]

39. Attal, N.; Cruccu, G.; Baron, R.; Haanpää, M.; Hansson, P.; Jensen, T.S.; Nurmikko, T. EFNS guidelines on the pharmacological treatment of neuropathic pain: 2010 revision. Eur. J. Neurol. 2010, 17, 1113-e88. [CrossRef] [PubMed]

40. Oosterling, A.; te Boveldt, N.; Verhagen, C.; van der Graaf, W.T.; Ham, M.V.; der Drift, M.V.; Vissers, K.; Engels, Y. Neuropathic Pain Components in Patients with Cancer: Prevalence, Treatment, and Interference with Daily Activities. Pain Pract. 2016, 16, 413-421. [CrossRef]

41. Giovannini, S.; Coraci, D.; Brau, F.; Galluzzo, V.; Loreti, C.; Caliandro, P.; Padua, L.; Maccauro, G.; Biscotti, L.; Bernabei, R. Neuropathic Pain in the Elderly. Diagnostics 2021, 11, 613. [CrossRef]

42. Giovannini, S.; van der Roest, H.G.; Carfi, A.; Finne-Soveri, H.; Garms-Homolová, V.; Declercq, A.; Jónsson, P.V.; van Hout, H.; Vetrano, D.L.; Gravina, E.M.; et al. Polypharmacy in Home Care in Europe: Cross-Sectional Data from the IBenC Study. Drugs Aging 2018, 35, 145-152. [CrossRef]

43. Onder, G.; Giovannini, S.; Sganga, F.; Manes-Gravina, E.; Topinkova, E.; Finne-Soveri, H.; Garms-Homolová, V.; Declercq, A.; van der Roest, H.G.; Jónsson, P.V.; et al. Interactions between drugs and geriatric syndromes in nursing home and home care: Results from Shelter and IBenC projects. Aging Clin. Exp. Res. 2018, 30, 1015-1021. [CrossRef] [PubMed]

44. Allemani, C.; Weir, H.K.; Carreira, H.; Harewood, R.; Spika, D.; Wang, X.-S.; Bannon, F.; Ahn, J.V.; Johnson, C.J.; Bonaventure, A. CONCORD Working Group. Global surveillance of cancer survival 1995-2009: Analysis of individual data for 25,676,887 patients from 279 population-based registries in 67 countries (CONCORD-2). Lancet 2015, 385, 977-1010. [CrossRef]

45. Coraci, D.; Fusco, A.; Frizzierro, A.; Giovannini, S.; Biscotti, L.; Padua, L. Global approaches for global challenges: The possible support of rehabilitation in the management of COVID-19. J. Med. Virol. 2020, 92, 1739-1740. [CrossRef] [PubMed]

46. Duregon, F.; Vendramin, B.; Bullo, V.; Gobbo, S.; Cugusi, L.; Blasio, A.D.; Neunhaeuserer, D.; Zaccaria, M.; Bergamin, M.; Ermolao, A. Effects of exercise on cancer patients suffering chemotherapy-induced peripheral neuropathy undergoing treatment: A systematic review. Crit. Rev. Oncol. Hematol. 2018, 121, 90-100. [CrossRef]

47. Vollmers, P.L.; Mundhenke, C.; Maass, N.; Bauerschlag, D.; Kratzenstein, S.; Röcken, C.; Schmidt, T. Evaluation of the effect of sensorimotor exercise on physical and psychological parameters in breast cancer patients undergoing neurotoxic chemotherapy. J. Cancer Clin. Oncol. 2018, 144, 1785-1792. [CrossRef]

48. Schwenk, M.; Grewal, G.S.; Holloway, D.; Muchna, A.; Garland, L.; Najafi, B. Interactive sensor-based balance training in older cancer patients with chemotherapy-induced peripheral neuropathy: A randomized controlled trial. Gerontology 2016, 62, 553-563. [CrossRef] [PubMed] 